\title{
Determinants of overburdening among informal carers: a systematic review
}

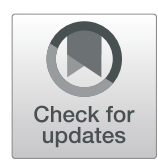

Nienke Lindt ${ }^{1}$, Jantien van Berkel ${ }^{2}$ and Bob C. Mulder ${ }^{3^{*}}$ (D)

\begin{abstract}
Background: The world's population is ageing, resulting in rising care demands and healthcare costs, which in turn lead to a shift from formal to informal care. However, not only is the number of potential informal carers fast decreasing, but also informal caregivers are experiencing a higher caregiver burden. This literature review aims to synthesize the literature on the common determinants of caregiver burden in Western countries, to help ensure future continuation of informal care in the home context, and to improve or sustain the quality of life of caregivers and patients alike.

Method: A systematic review of peer-reviewed articles included in PubMed, Scopus, and/or Psychlnfo was conducted.

Results: Seventeen articles were included. The most important predictors were the duration of caregiving and the patient's dependency level, in terms of both physical and mental dependency stemming from decreased cognitive capacity or behavioural problems. Some specific illnesses and role conflicts or captivity also increased caregiver burden, whereas social support lowered it. Being a female caregiver or having an adultchild relationship led to a higher burden.

Conclusions: The most important predictors of caregiver burden are the duration of caregiving and the patient's dependency level. In addition, the patient's behavioural problems and cognitive capacity determine dependency level, and thus care burden. Interventions to relieve burden need to be adapted to the illness trajectory of specific diseases and corresponding needs for social support for both the recipient and the caregiver. Changing role expectations, leading to men being more involved, could reduce the disproportionately high burden for women.
\end{abstract}

Keywords: Informal care, Stress, Burden, Antecedents, Adapted stress model

\section{Background}

The world's population is ageing, and the percentage of older people will continue to rise in the coming years. Whereas the percentage of people aged 65 or higher was $9.1 \%$ among the world's population in 2019, it is estimated that in 2050 older people will account for 15.9\%. In Europe and Northern America, by 2050 one in four persons could be aged 65 years or over. Moreover, within that same timeframe, the number of people aged

\footnotetext{
*Correspondence: bob.mulder@wur.nl

${ }^{3}$ Strategic Communication Group, Wageningen University, Hollandseweg 1,

6706 KN, P.O. Box 8130, 6700, EW, Wageningen, The Netherlands

Full list of author information is available at the end of the article
}

80 years or over is expected to triple from 143 million in 2019 to 426 million worldwide [1]. Because of the ageing population, the demand for care is also rising. It has been established that, as people age, they suffer from more (chronic) illnesses, needing long-term care. Among people aged 65 years or older, $70 \%$ suffer from a chronic disease. In the population aged 75 years or older suffering from a chronic disease, $63 \%$ have two or more chronic illnesses [2]. This results in the care volume increasing by $4 \%$ every year in the time period $2000-2010$, leading to higher overall healthcare costs [3].

(c) The Author(s). 2020 Open Access This article is licensed under a Creative Commons Attribution 4.0 International License, which permits use, sharing, adaptation, distribution and reproduction in any medium or format, as long as you give appropriate credit to the original author(s) and the source, provide a link to the Creative Commons licence, and indicate if changes were made. The images or other third party material in this article are included in the article's Creative Commons licence, unless indicated otherwise in a credit line to the material. If material is not included in the article's Creative Commons licence and your intended use is not permitted by statutory regulation or exceeds the permitted use, you will need to obtain permission directly from the copyright holder. To view a copy of this licence, visit http://creativecommons.org/licenses/by/4.0/ The Creative Commons Public Domain Dedication waiver (http://creativecommons.org/publicdomain/zero/1.0/) applies to the data made available in this article, unless otherwise stated in a credit line to the data. 


\section{Informal care}

In order to face these rising care demands and healthcare costs, Western governments are steering away from formal care and towards informal care. Consequently, older people are encouraged to stay at home longer instead of moving into nursing homes. In order to make this feasible, such people will have to rely on their direct network of family and friends to ensure informal care [4]. Given the trend of an ageing society and policy reforms, the need for informal care will increase in the coming years.

But how can informal care be defined? Informal care consists of all aid to a person in need of care from someone in his or her direct environment. This also entails less intensive help, help towards members of the household, and help towards institutional residents. Informal care goes further than so-called regular help. Regular help the aid that may reasonably be expected towards members of the household - means, for instance, the care for children. Examples of informal care activities are emotional support, administrative help, guidance in arranging appointments, transport, domestic and personal care [5]. It should be stressed that informal care is unpaid, results from social rather than professional relations, and entails long-term care for sick family members or friends [6].

In 2014, more than a third of the European population (34.3\%) gave some type of informal care. Most informal carers are aged between 50 and 75 and take care of partners or parents (in law) [7]. The largest group of people in need of informal care are those aged 75 and over [8].

Even though the need for informal carers is rising, current research reports that the potential support ratio - defined as the number of people of working age (25 to 64 years) per person aged 65 years or over - is rapidly decreasing. By 2050, it is estimated that, for 48 Western countries, the potential support ratio will have more than halved to below two; this means fewer than two potential informal carers per elderly person [1].

\section{Caregiver burden}

Besides the pressing future shortage of informal carers, Dutch research has shown that almost one in 10 informal carers feels overloaded with the care demand. Even though research also stresses the dual nature of informal caregiving, thus having both negative and positive aspects (e.g. [9, 10]), one in four providing long-term and intensive informal care feels stressed out. Not only do they feel as if the care demand is never lifted from their shoulders, but also they struggle with the upkeep of their own household and thus become overstrained [11]. These figures are alarming, especially as the Dutch healthcare system and its formal care services are advanced relative to other countries.

Caregiver burden can be defined [12] as 'a multidimensional response to the negative appraisal and perceived stress resulting from taking care of an ill individual' (p. 846). Overburdening threatens both the physical and the psychological health of caregivers. It has been shown that overstrained caregivers use more healthcare services and prescribed medication than noncaregivers, indicating a decline in physical health [13]. Moreover, stressed caregivers report more feelings of depression, perceived lack of coping mechanisms, and concerns about their poor quality of life [14]. If this burden is combined with the decreasing number of potential informal carers, it becomes apparent that the caregiver burden needs to be alleviated in order to cope with the future rising demand for informal care.

\section{Research objective}

Research has already been undertaken regarding the determinants of informal caregiver burden. However, most literature reviews have focused on homogeneous diagnostic groups. For instance, a systematic review that focused on caregiver burden in dementia [15] led to several categories of both patient and caregiver determinants, such as the patient's need for support, (cognitive) function disorders, and the caregiver's social functioning, self-efficacy, and coping traits. Other reviews have focused on caring for elderly patients with cancer [16], amyotrophic lateral sclerosis [17], Parkinson's disease [18], and mental disorders including bipolar disorder [19] and eating disorders [20]. Caregiver burden may indeed vary across diseases; however, exclusively focusing on specific diseases limits the identification of common determinants of caregiver burden across diseases [21].

The lack of knowledge on common determinants may hamper the development of effective policies and interventions that aim to relieve caregiver burden. Current interventions generally focus on providing caregivers with both direct and indirect support, such as emotional support, advice on coping, and respite services to reduce the amount of care burden [22]. However, systematic reviews on such interventions show that the effects on caregiver burden are very small or even insignificant $[23,24]$.

To inform future policy and intervention development, the aim of the present review is to synthesise the literature on the common determinants of caregiver burden in Western countries, to ultimately ensure future continuation of informal care in the home context, and to improve or sustain the quality of life of caregivers and patients alike. The literature review aims to answer the following research question: What are the determinants of caregiver burden among informal carers?

\section{Hypotheses}

Given its multidimensionality, the caregiver burden construct has many different definitions. According to George and Gwyther [25], it entails physical, psychological, 
emotional, financial, and social stressors that individuals experience because of providing care. Depending on the scope of the research and included facets, the caregiver burden definition differs per study [26].

Moreover, the distinction between objective and subjective burden adds to the complexity of the caregiver burden construct. Montgomery, Gonyea, and Hooyman [27] state that: 'objective burden is defined as the extent of disruptions or changes in various aspects of the caregivers' life and household. Subjective burden is defined as the caregivers' attitudes toward or emotional reactions to the caregiving experience' (p. 21). Thus, objective burden entails overt aspects, such as time spent on caregiving and the nature and number of tasks, whereas subjective burden encompasses caregiver perceptions of the care demands and their consequences, such as negative mood states and anxiety.

The multidimensionality of, and the objective-subjective distinction within, caregiver burden are both reflected in the Adapted Stress Model (ASM). The ASM describes the relationships between various categories of determinants that ultimately cause perceived caregiver burden (Fig. 1). Causality between the different constructs is implied from the left side of the ASM to the right, i.e. stressors positively affect caregiver burden, meaning that caregivers experience more stress than non-caregivers.

The ASM is based on stress theories, notably the transactional model of stress and coping [28] and the stress process model [29], as well as role theory [30].

Going from the left side of the model to the right, the ASM allows for the formulation of specific hypotheses, including their rationale.
H1: direct effects of stressors on perceived caregiver burden Whereas $\mathrm{H} 2, \mathrm{H} 3$, and $\mathrm{H} 4$ describe indirect (i.e. mediated) effects of general stressors through role and intrapsychic stressors, it is hypothesised that each class of stressor in the ASM may also directly result in perceived caregiver burden.

\section{H2: general stressors result in an estimated number of hours spent on caregiving}

The general stressors are the patient's cognitive status, problematic behaviour, dependency level, specific illness, and care demands. Together, these five general stressors lead to the caregiver's primary appraisal of the severity of the stressor [28], which translates into the estimated number of hours that need to be spent on caregiving.

\section{H3: the estimated number of caregiving hours leads to role conflict and role overload}

As a result of the estimated number of caregiving hours, caregivers may experience role conflict and role overload as role stressors. Role conflicts occur when the expectations of the various roles fulfilled by the caregiver become incompatible [30]. Theoretically, this is in line with secondary appraisal in the transactional model of stress and coping, which is the appraisal of one's resources (e.g. time) to manage the stressor [28]. In the case of informal care, the informal carer role may lead to conflict with the roles of being a parent or being an employee.

Role overload happens when people lack sufficient resources and time to fulfil all obligations linked to their roles [31]. For instance, an increase in the number of caregiving hours may result in role overload when the

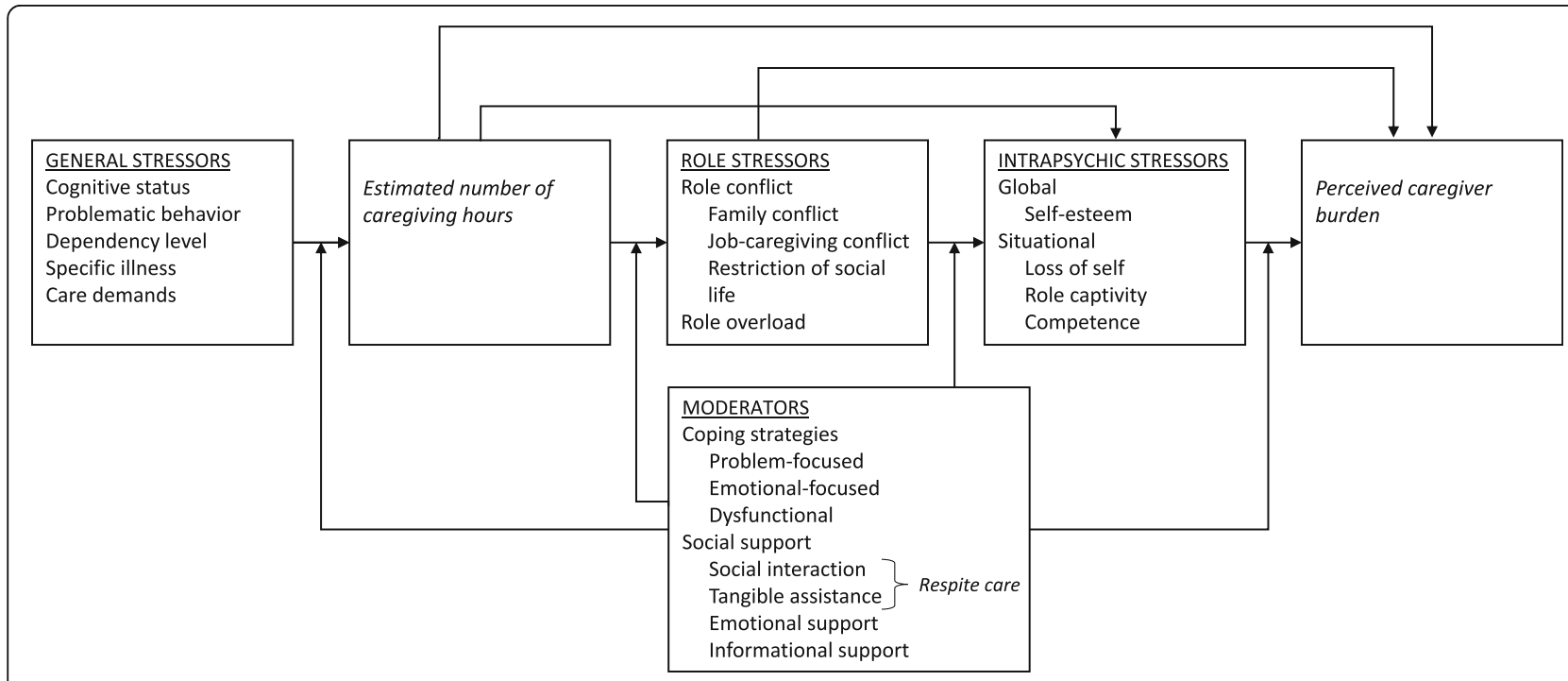

Fig. 1 Adapted Stress Model 
caregiver feels he or she lacks sufficient hours in the day to complete all tasks associated with every role he or she occupies.

\section{H4: role stressors may lead to intrapsychic stressors}

Role conflict and overload may result in role captivity, the feeling of entrapment within the caregiving role and the related experience of self-loss [32]. For instance, caregivers may give up activities related to other roles, such as quality time with their partner, in order to take care of their ill parent. It has been established that role captivity and loss of self can lead to higher feelings of depression and burden [32, 33]. In addition to this situational burden, role and intrapsychic stressors may negatively affect self-esteem and feelings of competence.

\section{H5: coping strategies and social support moderate the relationships between stressors and perceived caregiver burden}

Finally, the relationships between stressors and perceived caregiver burden may be moderated by coping strategies and perceived social support. Coping can be defined as the cognitive, emotional, and behavioural efforts to manage the internal and the environmental demands that challenge or exceed someone's resources [28]. According to Carver, Scheier, and Weintraub [34], coping efforts can be divided into three categories: problem-focused coping, emotional-focused coping, and dysfunctional coping. Problem-focused coping entails strategies used to solve certain problems, such as thinking about the steps that need to be taken in order to solve the problem. When the caregiver tries to reduce or eliminate negative feelings connected to the role, such as through seeking distraction, this can be considered a type of emotional-focused coping. Lastly, dysfunctional coping happens when people do not accept the problem at hand and try to ignore or even deny reality, and this is positively associated with feelings of anxiety, depression, and perceived burden $[35,36]$. In contrast, problem-focused coping does not appear to be related to caregiver burden [36, 37]. Whether emotional-focused coping and burden are related is not consistent in the current literature. However, cases of informal care among palliative cancer patients or people suffering from dementia show that emotional-focused coping leads to a decrease in perceived burden [37, 38].

Perceived social support is the second moderator in the ASM. In general, informal caregivers receiving social support from their own contacts or professionals experience less burden than others [39]. According to Thompson, Futterman, Gallagher-Thompson, Rose, and Lovett [40], social support that allows caregivers to engage in social interaction for fun and recreation is the most important in decreasing perceived burden. Other forms of social support are informational and emotional support and tangible assistance. Respite care is a special type of social support where social interaction and tangible assistance are combined. Here, the care tasks are temporarily lifted from the informal caregiver's shoulders in order to alleviate burden. Moreover, respite care should free up time, so caregivers can perform other roles. However, results on the effectiveness of respite care on caregiver burden are heterogeneous [41].

\section{Methods}

For this study, a systematic review was conducted. In this section, the methodology is described, consisting of a database search strategy, inclusion criteria, and a selection process. The first author (NL) developed the search strategy and performed the first search, which initially resulted in 13 articles. The search strategy (databases, search terms, and inclusion/exclusion criteria) was repeated independently by the second author (JvB). Differences were resolved by discussion, resulting in the addition of four more articles.

\section{Database search strategy}

Three databases were used for the literature search: Medline, PsycINFO, and Scopus. Medline and PsycINFO were searched simultaneously via EBSCOhost. In order to achieve relevant search hits, a field code (namely IT) was used in all databases. It was decided to ensure that the terms caregiver, carer, or caregiving AND burden, stress, strain, burnout, or overstrained were present in the title of the search hits. To narrow down the search results further, the articles had to be written in English, and published from 2013 onwards up to 31st of January 2019. A detailed overview of the search strategy can be found in Table 1. The multiple database search provided a total of 528 articles, after removing duplicates. The articles were then stored in an EndNote X8 database.

\section{Inclusion criteria}

In order to reach a final selection of articles, multiple inclusion criteria were established. Firstly, (i) caregiver burden needed to be a key concept in the study and had (ii) to include the multidimensionality of caregiver burden, corresponding with the theoretical framework of this research (i.e. include both objective burden measures (such as time spent on caregiving, the nature and number of tasks) and subjective burden measures (such as caregiver perceptions of the care demands and their consequences, such as negative mood states and anxiety)). In order to focus the literature review on the context of caregiving at home, (iii) studies with institutionalized or hospitalised patients (i.e. inpatients), were excluded. Moreover, (iv) the patients needed to be still alive during the research period in order to focus the 
Table 1 Search strategy (as conducted on 31st of January 2019)

\begin{tabular}{|c|c|c|c|}
\hline \multirow{3}{*}{$\begin{array}{l}\text { Database } \\
\text { Medline \& PsycINFO } \\
\text { via EBSCOhost }\end{array}$} & \multicolumn{2}{|c|}{ Search strategy } & \multirow{2}{*}{$\begin{array}{l}\text { Hits } \\
37,659\end{array}$} \\
\hline & $\# 1$ & TI caregiver OR TI carer OR TI caregiving & \\
\hline & $\# 2$ & Informal OR family OR spouse OR partner OR relative & $2,756,180$ \\
\hline & \#3 & $\begin{array}{l}\text { TI burden OR TI stress OR TI strain OR TI burnout OR } \\
\text { TI overstrained }\end{array}$ & 450,956 \\
\hline & $\# 4$ & Determinants OR factors OR causes OR reasons & $6,905,652$ \\
\hline & $\# 5$ & \#1 AND \#2 AND \#3 AND \#4 & 1601 \\
\hline & \#6 & Limit \#5 to English AND from 2013 onwards & 659 \\
\hline \multirow[t]{6}{*}{ Scopus } & $\# 1$ & TI caregiver OR TI carer OR TI caregiving & 28,197 \\
\hline & $\# 2$ & Informal OR family OR spouse OR partner OR relative & $4,048,355$ \\
\hline & \#3 & $\begin{array}{l}\text { TI burden OR TI stress OR TI strain OR TI burnout OR } \\
\text { TI overstrained }\end{array}$ & 744,861 \\
\hline & \#4 & Determinants OR factors OR causes OR reasons & $10,995,149$ \\
\hline & \#5 & \#1 AND \#2 AND \#3 AND \#4 & 1049 \\
\hline & \#6 & Limit \#5 to English AND from 2013 onwards & 459 \\
\hline \multirow[t]{2}{*}{ Overview } & & Total number combined records & 1.118 \\
\hline & & Records after removing duplicates & 528 \\
\hline
\end{tabular}

research on caregiver burden during caregiving (i.e. no retrospective orientation). Next, (v) only studies that examined associations between informal care and some measure of burden or stress were included, and (vi) articles had to report empirical research with a minimum of 100 respondents to ensure that statistical relationships and differences were relevant and representative for a whole population. Rather than calculating statistical power using minimum effect sizes of interest, this cutoff point was based on the reasoning that multivariate statistical techniques require at least 15-20 observations per predictor variable [42], and that the number of predictor variables including demographics is at least 6 .

Furthermore, (vii) the research had to be conducted in a Western country, because the presumed societal and cultural differences between Western and non-Western countries might play a role in informal care. Lastly, the articles had (viii) to be published in a peer-reviewed journal.

\section{Selection process}

As a first step of the selection process, the abstracts of the articles were screened on the established inclusion criteria. This resulted in a preliminary selection of $30 \mathrm{ar}-$ ticles. Then, the full texts of this selection were critically analysed based on the same inclusion criteria. From this, another 13 articles were omitted, resulting in a final selection of 17 articles for the current literature review (Fig. 2). An overview of the included articles can be found in Additional file 1.

\section{Results}

Of the 17 included studies, 14 published cross-sectional studies and three reported longitudinal studies. Thirteen studies measured caregiver burden via validated research instruments. Four studies used only one instrument: the Zarit Burden Interview (ZBI). This specific instrument was used in every paper that reported on caregiver burden in dementia care. An exception was Laporte Uribe's article [43], which used BIZA-D as an alternative to ZBI. A descriptive table with all included studies can be found in Additional file 1. In this section, the results regarding stressors, moderators, miscellaneous factors, and background characteristics are discussed.

\section{General stressors}

The three longitudinal studies all found that the duration of caregiving and the patient's functional status were the strongest determinants of burden [44-46]. In each longitudinal study, caregiver burden increased nonlinearly over time, as perceived burden increased at a steeper rate as time progressed. This shows that duration is an important factor. Guerriere et al. [44] argued that this might be caused by the progression of the care recipient's disease. However, it can also be hypothesised that duration has a more direct effect on caregiver burden, independent of disease progression; the burden becomes heavier the longer caring tasks are performed. This, then, could be explained via $\mathrm{H} 3$, where duration is expected to increase role overload.

Moreover, these three longitudinal studies as well as six of the 14 cross-sectional studies considered the patient's functional status in terms of dependency level in activities of daily living (henceforth shortened to ADL) as one of the strongest predictors of perceived caregiver burden [43-51]. This is consistent with the ASM, where ADL dependency is considered a general stressor. The influence of dependency 


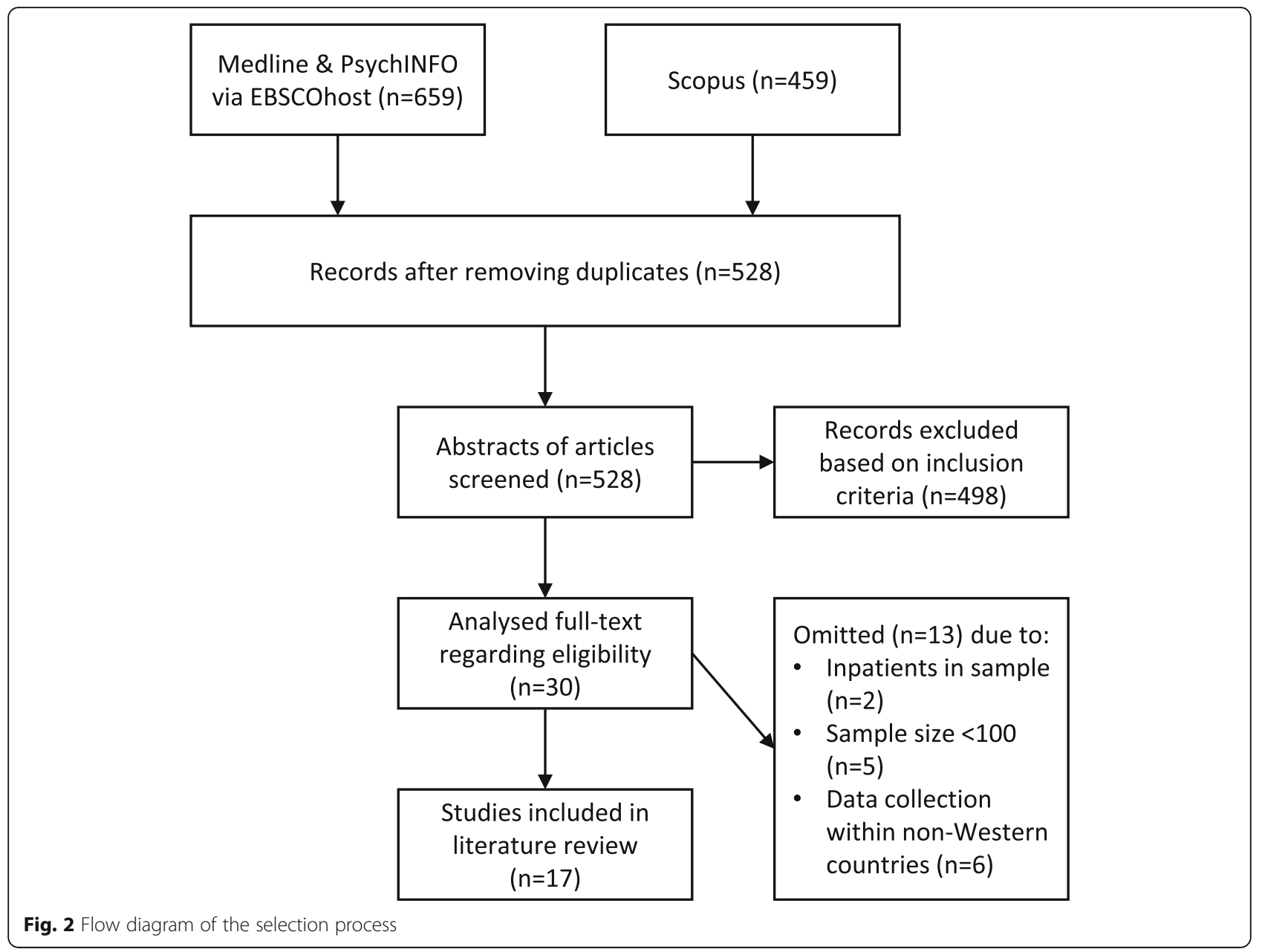

level could be explained via an increase in both the intensity of caregiving and the number of caregiving tasks required, leading to higher burden [44, 47]. Lethin et al. [45] linked ADL dependency in their longitudinal study specifically with increased need for supervision hours in the case of dementia care, providing support for $\mathrm{H} 2$.

In contrast to the duration of caregiving, the role of hours spent on caregiving per week or month showed mixed results. De Almeida Mello et al.'s [48] and Blanthorn et al.'s [52] cross-sectional research and Lethin et al.'s [45] and Guerriere et al.'s [44] longitudinal studies considered hours spent on caregiving a determinant of caregiver burden. However, Riffin et al.'s cross-sectional study [51] reported that time spent is no longer associated with caregiver burden after accounting for the number of caregiving tasks. According to them, the allocation of additional responsibilities may be more taxing on the informal carer than the time demand. From this, it can at least be hypothesised that more indirect factors, such as the number of tasks, influence caregiver burden and the perceived time demands.
Another factor that influenced informal caregiver burden is the specific illness of the patient. This is confirmed by four studies that claim that illnesses such as dementia, solid tumours, physical disabilities, or the presence of comorbidities are positively associated with burden $[46,53]$. This confirms the place of specific illness as a general stressor in the ASM and supports H1, i.e. general stressors (such as specific illness) have direct effects on perceived burden in addition to the indirect effects identified in $\mathrm{H} 2, \mathrm{H} 3$, and $\mathrm{H} 4$.

Finally, the care recipient's mental state - behaviour and cognitive capacity - appeared to be relevant [43, 45 , $46,54]$. This matches with the ASM, where these factors are labelled as general stressors, and again confirms the direct effects of behaviour and cognitive capacity on burden as formulated in H1. Both Ransmayr et al.'s [46] and Lethin et al.'s [45] longitudinal studies and Laporte Uribe et al.'s cross-sectional studies [43] incorporated patient's behavioural problems such as agitation and aggression in their research, and this proved to be positively related to caregiver burden. These factors 
seem especially relevant in the context of dementia care, where such behavioural problems occur frequently.

Besides behaviour, three articles, both longitudinal and cross-sectional, reported on care recipients' cognitive capacity $[45,48,55]$. From the research in these articles, it becomes apparent that the patient's cognitive status indeed has predictive value for caregiver burden; reduced cognitive function in the recipient leads to higher burden.

In conclusion, all general stressors included in the ASM have direct effects on caregiver burden, supporting H1. Studies on dependency level as a stressor provided indirect support for $\mathrm{H} 2$, in addition to one study that specifically confirmed that dependency level translated into an estimation of the needed supervision hours.

\section{Role and intrapsychic stressors}

Ransmayr et al. [46] found in their longitudinal study that burden also builds over time as a result of restrictions on caregivers' time for other activities and psychological distress. This could be linked to role theory, entailing both role conflict, which most likely is the case when less time is available for other activities, and role captivity or role overload, referring to psychological distress.

The relevance of role conflict is confirmed by three cross-sectional studies that firstly showed the influence of job-caregiving conflicts, which are incorporated as one type of role conflict in the ASM [48, 50, 56]. Their research showed not only that informal carers who combine work and care experience the highest burden [56], but also that a higher ADL dependency in combination with employment is positively related to caregiver stress [50]. Secondly, De Almeida Mello et al.'s cross-sectional study [48] confirmed that both job-caregiving conflict and revealed family conflict positively influence caregiver burden, which is also a type of role conflict.

Taken together, these studies support $\mathrm{H} 3$ and H4; informal care may lead to both role conflict and role overload, and these, in turn, may result in additional intrapsychic stressors. Moreover, the cross-sectional studies provide support for $\mathrm{H} 1$, as role conflict directly affects burden.

\section{Social support as moderator}

Five studies, both longitudinal and cross-sectional, included social support in their research $[43,44,50,51$, 55]. It was found that a higher quality of support, both formal and informal, for the caregiver is associated with lower burden, whereas unmet needs for health and social services contribute to caregiver burden [55]. Moreover, Hsu et al.'s cross-sectional research [50] referred to the importance of social support aimed at the patient leading to lower caregiver burden. From this, it can be deduced that it is important to ensure that both the caregiver and the recipient feel well supported both by the direct environment and by available professionals. Surprisingly, the articles did not explain, either in theory or via empirical testing, the exact mechanisms that cause social support to affect caregiver burden. However, the fact that social support at least correlates negatively with burden partly supports $\mathrm{H} 5$ about the moderating effect of social support on the stressor-burden relationship. No studies addressed the effects of specific coping strategies on care burden.

The specific role of respite services showed some mixed results at first glance. Guerriere et al.'s longitudinal research [44] found that a patient's number of hospice days were negatively related to caregiver burden; the more days a patient spent in a hospice instead of at home, the lower the burden for the informal caregiver. Hospices are often used as a type of social support or respite service, where patients are admitted during the day or for several days in the week to alleviate the carer's care responsibilities. However, Riffin et al.'s crosssectional research [51] showed a positive relationship between using respite services and burden. This seems like contradictory evidence, but it should be stated that causality cannot be determined from cross-sectional research. Therefore, it could be argued that a positive relationship is found consequent to the progression of the disease, which indirectly influences the need for, and use of, respite services because of the intensity of caring. These potential effects of the general stressors on the moderators have not been hypothesised.

\section{Miscellaneous factors}

De Almeida Mello et al.'s cross-sectional research [48] was especially interesting for the current literature review, as they based their empirical research on Bastawrous' [26] recommendations, which were also used for the ASM in this review. They used the factors from Pearlin et al.'s stress process model [29] as input for their research, in addition to potential determinants from role theory. Additional factors that appeared relevant in their research, besides the already mentioned determinants, were depressive symptoms, previous admissions to nursing homes, risk of falls, cohabitation, and an adult-child relationship between the caregiver and the care recipient. These all had a positive relationship with caregiver burden; this can be interpreted as support for H4. Lethin et al. [45] and Juntunen et al. [55] confirmed that (risk of) depression correlates with caregiver burden, especially among men in Juntunen et al.'s research [55]. However, whether cohabitation and the relationship between caregiver and patient are significant determinants of caregiver burden is disputed in the included articles. 
In the cross-sectional and longitudinal studies of Braich et al. [47], Guerriere et al. [44], and Hsu et al. [50], the relationship between caregiver and care recipient appeared irrelevant. In contrast, Riffin et al. [51] and Laporte Uribe et al. [43] in their cross-sectional studies found that an adult-child relationship leads to higher burden. These contradictory results could be explained by the presence of different types of burden. Two crosssectional studies identified different types of burden via exploratory factor analysis [56, 57]. According to them, caregivers experience different types of burden depending on the specific kinship role. This is in line with, for instance, Juntunen et al.'s cross-sectional research [55] where differences were found in the determinants of caregiver burden for spouses, daughters, and mothers of the care recipient. Therefore, the relationship type between caregiver and recipient can be considered relevant and would most likely be a valuable addition to the ASM.

Lastly, Guerriere et al.'s longitudinal research [44] found living arrangements, such as cohabitation, to be insignificant. However, Ransmayr et al. [46] in their longitudinal research state that the physical proximity of the patient correlates positively with caregiver burden. Here, results remain inconclusive, and unambiguous conclusions on living distance cannot be drawn.

\section{Background characteristics}

Finally, some interesting background characteristics were researched in the selected articles. Seven of the 17 articles indicated that being a female caregiver correlates positively with caregiver burden. In other words, female caregivers experience more subjective burden than male caregivers. Whether the sex of the patient and the age of the caregiver and the patient are also relevant cannot be concluded, as results were inconclusive. However, the overall health, well-being, and quality of life of the caregiver proved to be important. For instance, Riffin et al.'s research [51] found that caregivers in poor health or with anxiety symptoms experience higher informal caregiver burden.

\section{Discussion}

The aim of the present review was to update and synthesize the literature on the common determinants of the caregiver burden, to ultimately ensure the future continuation of informal care in the home context, and improve or sustain the quality of life of caregivers and patients alike. This systematic review tests, and provides evidence for, the ASM in Western countries.

In the studies included in the literature review, all of the determinants incorporated in the ASM were found to have direct effects on caregiver burden, providing strong support for $\mathrm{H} 1$. The most important predictors of caregiver burden were the duration of caregiving and the patient's dependency level. The longer someone had to provide informal care or the more dependent the patient became, the higher the perceived burden. Besides physical dependency, the recipient's mental state in terms of behavioural problems and cognitive capacity was also a determinant of dependency level, and these were positively related to caregiver burden. Some specific illnesses, such as dementia or solid tumours, also led to a higher burden.

Even though duration of caregiving proved to be an important predictor of caregiver burden, the support for $\mathrm{H} 2$ was more mixed, partly because time spent on caregiving appeared to be an ambiguous construct; studies reported either the total duration of caregiving or the hours spent per week or month. Only one study found evidence that the stressor, dependency level, resulted in an estimate of the number of care hours to be spent. Even though both duration and time spent were positively related to caregiver burden, the exact reasons for these effects are not fully clarified. Duration of caregiving would be a valuable addition to the ASM.

Potential explanations for the effects of duration of, and time spent on, caregiving were progression of the disease, role captivity, or role conflicts, indirectly supporting H3. In addition, the presence of role conflicts or role captivity also increased informal caregiver burden. However, the articles did not investigate the causal relationship between role stressors and intrapsychic stressors, so no definitive answer can be given regarding H4. Social support seemed to lower the perceived burden thanks to its moderating role on the relationship between stressors and perceived burden. No studies reported on the effect of coping strategies on caregiver burden; therefore, H5 is only partially supported. In terms of background characteristics, female caregivers experienced more stress over time. In addition, different kinship roles led to different types of caregiver burden. Therefore, the relationship type between caregiver and care recipient should be added to the ASM. Lastly, it should be noted that many findings were discussed as covariates in the articles, but causal relationships could not be derived, as the studies did not determine causality both theoretically and via empirical testing.

\section{Academic relevance}

Adelman et al. [21] published a clinical review about determinants (which they termed risk factors) of caregiver burden in 2014. When comparing the outcomes of the current literature review with that clinical review of a few differences stand out (see Table 2 for an overview). First, as Adelman et al. provide risk factors for caregiver burden, they only address hypothesis 1 from the ASM: a direct effect of stressors on caregiver burden. The 
Table 2 Synthesis of determinants of caregiver burden: comparison between Adelman et al. (2014) [21] and the current review

\begin{tabular}{|c|c|c|c|c|c|}
\hline \multicolumn{3}{|l|}{ Adelman et al. (2014) ${ }^{a}$ [21] } & \multicolumn{3}{|l|}{ Current review } \\
\hline $\begin{array}{l}\text { Hypothesis ASM }{ }^{\text {b }} \text { (support } \\
\text { found, no support found) }\end{array}$ & Categorisation & Risk Factors & Determinants & $\begin{array}{l}\text { Categorisation } \\
(\text { ASM) }\end{array}$ & $\begin{array}{l}\text { Hypothesis ASM }{ }^{\text {b }} \\
\text { (support found, no support found) }\end{array}$ \\
\hline \multirow[t]{3}{*}{ H1 (direct relation) } & Demographics & Female sex & Female sex & $\begin{array}{l}\text { Background } \\
\text { characteristic }\end{array}$ & H1 (direct relation) \\
\hline & & Low education & - & & \\
\hline & & $\begin{array}{l}\text { Cohabitation with care } \\
\text { recipient }\end{array}$ & $\begin{array}{l}\text { Cohabitation/Living } \\
\text { distance }\end{array}$ & $\begin{array}{l}\text { Miscellaneous } \\
\text { factor }\end{array}$ & Inconclusive \\
\hline \multirow[t]{4}{*}{$\mathrm{H} 1$ (direct relation) } & Psychosocial & Coping strategies & Coping strategies & Moderators & $\begin{array}{l}\text { H1 (direct relation) } \\
\text { H5 partially supported: no } \\
\text { moderation of coping strategies }\end{array}$ \\
\hline & & - & Social Support & & $\begin{array}{l}\text { H5 partially supported: moderation } \\
\text { of social support }\end{array}$ \\
\hline & & $\begin{array}{l}\text { Depression and } \\
\text { depressive symptoms }\end{array}$ & $\begin{array}{l}\text { Global (self-esteem) } \\
\text { Situational (loss of self, } \\
\text { competence) }\end{array}$ & $\begin{array}{l}\text { Intrapsychic } \\
\text { stressors }\end{array}$ & $\begin{array}{l}\text { H1 (direct relation) } \\
\text { H4 (mediation) not supported }\end{array}$ \\
\hline & & $\begin{array}{l}\text { Perceived patient } \\
\text { distress }\end{array}$ & - & & \\
\hline \multirow[t]{9}{*}{ H1 (direct relation) } & $\begin{array}{l}\text { Caregiving } \\
\text { context }\end{array}$ & $\begin{array}{l}\text { Social isolation and } \\
\text { decreased social } \\
\text { activity }\end{array}$ & $\begin{array}{l}\text { Role conflict } \\
\text { (Restriction of social life) }\end{array}$ & Role stressors & $\begin{array}{l}\mathrm{H} 1 \text { (direct relation) } \\
\mathrm{H} 3 \text { (mediator between duration of } \\
\text { caregiving and caregiver burden) }\end{array}$ \\
\hline & & $\begin{array}{l}\text { Inability to continue } \\
\text { regular employment }\end{array}$ & Role overload & & \\
\hline & & Financial stress & - & & \\
\hline & & Lack of choice & - & & \\
\hline & & $\begin{array}{l}\text { Caregiving time and } \\
\text { effort }\end{array}$ & Duration of caregiving & $\begin{array}{l}\text { General } \\
\text { stressors }\end{array}$ & $\begin{array}{l}\text { H1 (direct relation) } \\
\text { H3 (mediated by role stressors) }\end{array}$ \\
\hline & & - & Specific Illness & & \\
\hline & & - & $\begin{array}{l}\text { Dependency levels, } \\
\text { both physically as } \\
\text { mentally }\end{array}$ & & \\
\hline & & - & Care demands & & \\
\hline & & - & Problematic behavior & & \\
\hline
\end{tabular}

"Refers to risk factors of caregiver burden in Table 1 "The Epidemiology of Caregiver Burden" p1054 Adelman et al. (2014) [21]

${ }^{\mathrm{b}}$ The Adapted Stress Model (ASM) is based on stress theories, notably the transactional model of stress and coping (Lazarus, 1984) [28] and the stress process model (Pearlin, 1990) [29], as well as role theory (Biddle, 1986) [30]

current review also found support for these direct relations, but also found some support for an indirect (i.e. mediated) effect number of hours spent on caregiving ( $\mathrm{H} 2)$ and through role stressors (H3). In addition, support was found for a moderating effect of social support, on the relation between general stressors and caregiver burden (H5).

Next, Adelman et al. [21] focus on risk factors related to the caregiver (e.g., demographics, such as female sex and low education), and psychosocial factors (e.g., social isolation and decreased social activity). Although attention is also paid to the caregiving context (comprising risk factors such as caregiving time, and lack of choice of being a caregiver), these risk factors seem predominantly focussed on individual caregiver characteristics.

Adding to those insights, the current review found that care recipients' characteristics are also related to caregiver burden. Specifically, dementia, solid tumours, physical disabilities and the presence of comorbidity were associated with higher burden. The associations of these specific illnesses with caregiver burden could partly be explained by the different levels of care recipients' mental and/or physical dependency resulting from these illnesses, as these dependency levels have also been found to be relevant determinants of caregiver burden. This again confirms the importance of the specific illness as a general stressor of caregiver burden.

\section{Practical implications}

Based on this literature review, recommendations can be made for future interventions. Firstly, it is important to focus on the specific carers most at risk of caregiver burden, as research has shown that being a female informal caregiver, providing dementia care, and being a child's 
caregiver predict higher burden. Besides specific interventions for these groups, it appears that increased involvement of men in informal care would provide an opportunity to relieve the burden for female caregivers. The current social norm holds that women take up more caring tasks than men; however, such role expectations threaten the sustainability of informal care in light of rising care demands in the future.

Secondly, interventions could benefit from adaptation to the course of specific illnesses, as it appears that burden increases non-linearly over time. For example, it could be determined at which junctures during the illness trajectory interventions would be most needed to support caregivers. This could involve interventions on different levels, such as interventions aimed at the individual, where the focus could be on increasing the patient's independence both mentally and physically, and interventions aimed at the organisations involved in the caregiving trajectory.

\section{Future research}

Some interesting future research opportunities are indicated by this literature review, the outcomes of which could be used to optimise interventions aimed at relieving informal caregiver burden. First and foremost, experimental designs are needed to determine the causality between determinants. Specifically, the effects of different types of respite care could be tested experimentally regarding their effectiveness in relieving care burden.

Moreover, this research domain would benefit from more longitudinal studies, enabling trend analyses regarding the trajectory of informal caregiver burden over time. As the concept of time cuts straight through both the primary and the secondary stress appraisals, and contains both objective and subjective elements, time warrants further attention. For instance, it influences not only the appraisal of the stressful event of informal caring, but also the perceived hours available for other roles.

Lastly, during the selection process, it was noted that a large proportion of the research appeared to have been carried out in Asian countries, which have collectivistic cultures, and these studies were excluded from the current review. It would be interesting to conduct a comparative study between the Western and the Asian world in order to determine the relevance of cultural expectations for informal caregiver burden.

\section{Strengths and limitations}

Some limitations of this research should be noted. Firstly, most of the articles included in the systematic review consisted of cross-sectional research. This may be explained by the search strategy, in which we did not specify research designs (such as an RCT). Therefore, causality between the different concepts could not be determined properly. Due to this, the actual process or framework (via indirect effects) cannot be validated.

Secondly, a methodological limitation is the selection criterium for studies having at least a sample size of 100 subjects, a cut-off point that was somewhat arbitrary. Larger sample sizes would have increased statistical power (avoiding type I error). However, since some patient groups (and therefore also the caregivers groups) are relatively small, potentially relevant relationships may have been missed (increasing type II error) [58].

Furthermore, this study only included quantitative studies. More rich and in-depth insights on how caregiver burden comes about, could have been established by including qualitative studies. Thereby, the current review only tests the ASM, but does not expand it.

Other limitations are related to the search strategy. Firstly, using general search terms (i.e. not illnessspecific) was in line with the aim of the study to identify common causes of caregiver burden. However, we might have missed information on common causes identified in studies that were reporting on caregiver burden for a specific illness. Secondly, the search terms were informed by the Adapted Stress Model, which formed the theoretical underpinning for this review study. By making this choice, we may have missed articles referring to for example 'associations' instead of determinants, factors, causes or reasons. In addition, we may have missed articles that did not include the terms caregiver, carer or caregiving AND burden, stress, strain, burnout or overstrained in the title. Finally, using 2013 as the lower date limit in the search strategy can be considered an arbitrary choice. However, this was done in order to increase the relevance of our systematic review, since more recent studies might already have been affected by ongoing policy reforms that aim to lessen the burden on formal care, through stimulating informal care in the home context.

Lastly, the ASM, used as underpinning for this review, also has its limitations. For example, it does not take into account (personal) resources (such as self-efficacy etc.) which might also be relevant in predicting caregiver burden. Considering the multidimensionality of caregiver burden and its outcomes, this could have resulted in overlooking some determinants or working mechanisms.

However, overall, this systematic review also has certain strengths. In the vast and diverse array of articles available on the topic of informal caregiver burden, a focused selection has been made with a systematic and transparent search strategy. This strategy comprised of selecting only studies with large samples $(n>100)$, as those studies have larger explanatory (statistical) power than studies involving smaller samples. Moreover, this 
literature review has a strong theoretical framework, which already identified most of the determinants later found during the review. The reviewed studies thus provided more insights into if and how these determinants affect caregiver burden.

\section{Conclusions}

According to the present review, all determinants as described in the Adapted Stress Model have direct influences on caregiver burden. The strongest determinants of caregiver burden are the duration of caregiving, and the patient's dependency level. In addition, the patient's mental state, in terms of behavioural problems and cognitive capacity, determines dependency level, and thus care burden. Therefore, specific interventions should be designed for carers most at risk, which focus on increasing the patient's physical and mental independence. Interventions to relieve burden need to be adapted to the illness trajectory of specific diseases and corresponding needs for social support for both the recipient and the caregiver. Finally, changing role expectations, leading to men being more involved, could reduce the disproportionately high burden for women.

\section{Supplementary information}

Supplementary information accompanies this paper at https://doi.org/10. 1186/s12877-020-01708-3.

Additional file 1. Output literature review

\section{Abbreviations}

ADL: Activities of daily livingASMAdapted stress modelZBIZarit Burden Interview

\section{Acknowledgements}

Not applicable.

\section{Authors' contributions}

$\mathrm{NL}$ and BM set up the research protocol; NL and JVB independently carried out the literature search and selection; all authors critically reviewed the manuscript, and read and approved the final manuscript.

\section{Funding}

The study did not receive any external funding.

\section{Availability of data and materials}

All data generated or analysed during this study are included in this published article [and its supplementary information files].

\section{Ethics approval and consent to participate}

Not applicable.

\section{Consent for publication}

Not applicable.

\section{Competing interests}

The authors declare that they have no conflict of interest.

\section{Author details}

${ }^{1}$ Strategic Communication Group, Wageningen University, Hollandseweg 1, 6706, KN, Wageningen, The Netherlands. ${ }^{2}$ Consumption and Healthy Lifestyles, Wageningen University, Hollandseweg 1, 6706, KN, Wageningen,
The Netherlands. ${ }^{3}$ Strategic Communication Group, Wageningen University, Hollandseweg 1, 6706 KN, P.O. Box 8130, 6700, EW, Wageningen, The Netherlands.

Received: 12 July 2019 Accepted: 13 August 2020

Published online: 26 August 2020

\section{References}

1. World population prospects 2019. New York: United Nations, Affairs DoEaS; 2019.

2. Schumacher J. Cijfers: vergrijzing en toenemende zorg. Zorg voor Beter; 2017.

3. Van der Horst A, Van Erp F, De Jong J. Trends in gezondheid en zorg. Den Haag: Centraal Planbureau; 2011

4. 2015. Available from: https://wetten.overheid.nl/BWBR0035362/2018-11-17.

5. De Klerk M, De Boer A, Plaisier I, Schyns P, Kooiker S. Informele hulp: wie doet er wat? Den Haag: Sociaal en Cultureel Planbureau; 2015.

6. Wanneer ben ik mantelzorger? Mantelzorg 2018.

7. Verbakel E, Tamlagsrønning S, Winstone L, Fjær EL, Eikemo TA. Informal care in Europe: findings from the European social survey (2014) special module on the social determinants of health. Eur J Public Health. 2017; 27(suppl_1):90-5.

8. Putnam L, Verbeek-Oudijk D, De Klerk M. Zorg en ondersteuning in Nederland: kerncijfers 2014. Ontvangen hulp bij het huishouden, persoonlijke verzorging, verpleging en begeleiding. Den Haag: SCP; 2016.

9. Zarit SH. Positive aspects of caregiving: more than looking on the bright side. Aging Mental Health. 2012:16(6):673-4. https://doi.org/10.1080/ 13607863.2012 .692768

10. van Groenou MIB, de Boer A, ledema J. Positive and negative evaluation of caregiving among three different types of informal care relationships. Eur J Ageing. 2013;10(4):301-11.

11. De Klerk M, De Boer A, Plaisier I, Schyns P. Voor elkaar? Stand van de informele hulp in 2016. Den Haag: Sociaal en Cultureel Planbureau; 2017.

12. Kim H, Chang M, Rose K, Kim S. Predictors of caregiver burden in caregivers of individuals with dementia. J Adv Nurs. 2012:68(4):846-55.

13. Serrano-Aguilar PG, Lopez-Bastida J, Yanes-Lopez V. Impact on healthrelated quality of life and perceived burden of informal caregivers of individuals with Alzheimer's disease. Neuro-epidemiology. 2006:27(3): 136-42.

14. Molyneux GJ, McCarthy GM, McEniff S, Cryan M, Conroy RM. Prevalence and predictors of carer burden and depression in carers of patients referred to an old age psychiatric service. Int Psychogeriatr. 2008:20(6):1193-1202.

15. van der Lee J, Bakker TJ, Duivenvoorden HJ, Dröes R-M. Multivariate models of subjective caregiver burden in dementia: a systematic review. Ageing Res Rev. 2014;15:76-93.

16. Ge L, Mordiffi SZ. Factors associated with higher caregiver burden among family caregivers of elderly cancer patients: a systematic review. Cancer Nurs. 2017:40(6):471-8.

17. de Wit J, Bakker LA, van Groenestijn AC, van den Berg LH, Schröder CD, Visser-Meily JM, et al. Caregiver burden in amyotrophic lateral sclerosis: a systematic review. Palliat Med. 2018;32(1):231-45.

18. Leiknes I, Lien U-T, Severinsson E. The relationship between caregiver burden, demographic variables, and the clinical characteristics of patients with Parkinson's disease-a systematic review of studies using various caregiver burden instruments; 2015

19. Van Der Voort T, Goossens P, Van Der Bijl J. Burden, coping and needs for support of caregivers for patients with a bipolar disorder: a systematic review. J Psychiatr Ment Health Nurs. 2007;14(7):679-87.

20. Zabala MJ, Macdonald P, Treasure J. Appraisal of caregiving burden, expressed emotion and psychological distress in families of people with eating disorders: a systematic review. Eur Eating Disord Rev. 2009;17(5):338-49.

21. Adelman RD, Tmanova LL, Delgado D, Dion S, Lachs MS. Caregiver burden: a clinical review. Jama. 2014;311(10):1052-60.

22. Allen RS, M. MH, Ege MA, Shuster JL, Burgio LD. Legacy activities as interventions approaching the end of life. J Palliat Med. 2008:11(7):1029-38.

23. Candy B, Jones L, Drake R, Leurent B, King M. Interventions for supporting informal caregivers of patients in the terminal phase of a disease. Cochrane Database Syst Rev. 2011(6):CD007617. https://doi.org/10.1002/14651858. CD007617.pub2. 
24. Lopez-Hartmann M, Wens J, Verhoeven V, Remmen R. The effect of caregiver support interventions for informal caregivers of communitydwelling frail elderly: a systematic review. Int J Integr Care. 2012;12:e133. https://doi.org/10.5334/ijic.845.

25. George LK, Gwyther LP. Caregiver well-being: a multidimensional examination of family caregivers of demented adults. Gerontologist. 1986:26(3):253-9.

26. Bastawrous M. Caregiver burden - a critical discussion. Int J Nurs Stud. 2013: 50(3):431-41.

27. Montgomery RJV, Gonyea JG, Hooyman NR. Caregiving and the experience of subjective and objective burden. Fam Relat. 1985:34(1):19-26.

28. Lazarus RS, Folkman S. Stress, appraisal and coping. New York: Springer; 1984

29. Pearlin LI, Mullan JT, Semple SJ, Skaff MM. Caregiving and the stress process: an overview of concepts and their measures. Gerontologist. 1990:30(5):583-94.

30. Biddle BJ. Recent developments in role theory. Annu Rev Sociol. 1986:67-92.

31. Goode WJ. A theory of role strain. Am Sociol Rev. 1960;24:483-96.

32. Walker RV, Powers SM, Bisconti TL. Positive aspects of the caregiving experience: finding Hope in the midst of the storm. Women Ther. 2016; 39(3-4):354-70.

33. Noonan AE, Tennstedt SL. Meaning in caregiving and its contribution to caregiver well-being. Gerontologist. 1997:785-94.

34. Carver CS, Scheier MF, Weintraub JK. Assessing coping strategies: a theoretically based approach. J Pers Soc Psychol. 1989:56(2):267-83.

35. Cooper C, Balamurali TBS, Livingston G. A systematic review of the prevalence and covariates of anxiety in caregivers of people with dementia. Int Psychogeriatr. 2006;19(2):175-95.

36. Li R, Cooper C, Bradley J, Shulman A, Livingston G. Coping strategies and psychological morbidity in family carers of people with dementia: a systematic review and meta-analysis. J Affect Disord. 2012;139(1):1-11.

37. Perez-Ordóñez F, Frías-Osuna A, Romero-Rodríguez Y, Del-Pino-Casado R. Coping strategies and anxiety in caregivers of palliative cancer patients. Eur J Cancer Care. 2016:25(4):600-7.

38. Gilhooly KJ, Gilhooly MLM, Sullivan MP, Mclntyre A, Wilson L, Harding E, et al. A meta-review of stress, coping and interventions in dementia and dementia caregiving. BMC Geriatr. 2016:16(1):1-8.

39. Savage $S$, Bailey $S$. The impact of caring on caregivers' mental health: a review of the literature. Aust Health Rev. 2004;27(1):111-7.

40. Thompson EH, Futterman AM, Gallagher-Thompson D, Rose JM, Lovett SB. Social support and caregiving burden in family caregivers of frail elders. J Gerontol. 1993;48(5):S245-54.

41. Vandepitte S, Van Den Noortgate N, Putman K, Verhaeghe S, Verdonck C, Annemans L. Effectiveness of respite care in supporting informal caregivers of persons with dementia: a systematic review. Geriatric Psychiatry. 2016: 31(12):1277-88.

42. Siddiqui K. Heuristics for sample size determination in multivariate statistical techniques. World Appl Sci J. 2013;27(2):285-7

43. Laporte Uribe F, Heinrich S, Wolf-Ostermann K, Schmidt S, Thyrian JR, Schäfer-Walkmann S, et al. Caregiver burden assessed in dementia care networks in Germany: findings from the DemNet-D study baseline. Aging Ment Health. 2017:926-37.

44. Guerriere D, Husain A, Zagorski B, Marshall D, Seow H, Brazil K, et al. Predictors of caregiver burden across the home-based palliative care trajectory in Ontario, Canada. Health Soc Care Community. 2016:24(4):428-38.

45. Lethin C, Leino-Kilpi H, Bleijlevens MHC, Stephan A, Martin MS, Nilsson K, et al. Predicting caregiver burden in informal caregivers caring for persons with dementia living at home - a follow-up cohort study. Dementia. 2018: 19(3):640-60.

46. Ransmayr G, Hermann P, Sallinger K, Benke T, Seiler S, Dal-Bianco P, et al. Caregiving and caregiver burden in dementia home care: results from the prospective dementia registry (PRODEM) of the Austrian Alzheimer Society. J Alzheimer's Dis. 2018:63(1):103-14.

47. Braich PS, Jackson M, Knohl SJ, Bhoiwala D, Gandham SB, Almeida D. Burden and depression in caregivers of blind patients in New York state. Ophthalmic Epidemiol. 2016:162-70.

48. de Almeida MJ, Maca J, Van Durme T, Cès S, Spruytte N, Van Audenhove C, et al. The determinants of informal caregivers' burden in the care of frail older persons: a dynamic and role-related perspective. Aging Ment Health. 2017:838-43.

49. Flyckt $L$, Fatouros-Bergman $H$, Koernig $T$. Determinants of subjective and objective burden of informal caregiving of patients with psychotic disorders. Int J Soc Psychiatry. 2015;61(7):684-92.
50. Hsu T, Loscalzo M, Ramani R, Forman S, Popplewell L, Clark K, et al. Factors associated with high burden in caregivers of older adults with cancer. Cancer. 2014;120(18):2927-35.

51. Riffin C, Van Ness PH, Wolff JL, Fried T. Multifactorial examination of caregiver burden in a National Sample of family and unpaid caregivers. J Am Geriatr Soc. 2019;67(2):277-83.

52. Blanthorn-Hazell S, Gracia A, Roberts J, Boldeanu A, Judge D. A survey of caregiver burden in those providing informal care for patients with schizophrenia or bipolar disorder with agitation: results from a European study. Ann Gen Psychiatry. 2018:17:8.

53. Fridman M, Banaschewski T, Sikirica V, Quintero J, Erder MH, Chen KS. Factors associated with caregiver burden among pharmacotherapy-treated children/adolescents with ADHD in the caregiver perspective on pediatric ADHD survey in Europe. Neuropsychiatr Dis Treat. 2017;13:373-86.

54. Polenick CA, Martire LM. Caregiver attributions for late-life depression and their associations with caregiver burden. Fam Process. 2013;52(4):709-22.

55. Juntunen K, Salminen A-L, Törmäkangas T, Tillman P, Leinonen K, Nikander R. Perceived burden among spouse, adult child, and parent caregivers. J Adv Nurs. 2018:74(10):2340-50.

56. Unson C, Flynn D, Haymes E, Sancho D, Glendon MA. Predictors of types of caregiver burden. Soc Work Ment Health. 2016:14(1):82-101.

57. Cohen SA, Cook S, Kelley L, Sando T, Bell AE. Psychosocial factors of caregiver burden in child caregivers: results from the new national study of caregiving. Health Qual Life Outcomes. 2015:13(1):120.

58. loannidis JP. Why most published research findings are false. PLoS Med. 2005;2(8):e124.

\section{Publisher's Note}

Springer Nature remains neutral with regard to jurisdictional claims in published maps and institutional affiliations.

Ready to submit your research? Choose BMC and benefit from:

- fast, convenient online submission

- thorough peer review by experienced researchers in your field

- rapid publication on acceptance

- support for research data, including large and complex data types

- gold Open Access which fosters wider collaboration and increased citations

- maximum visibility for your research: over $100 \mathrm{M}$ website views per year

At $\mathrm{BMC}$, research is always in progress.

Learn more biomedcentral.com/submissions 